\title{
Journal of Biomedical Science
}

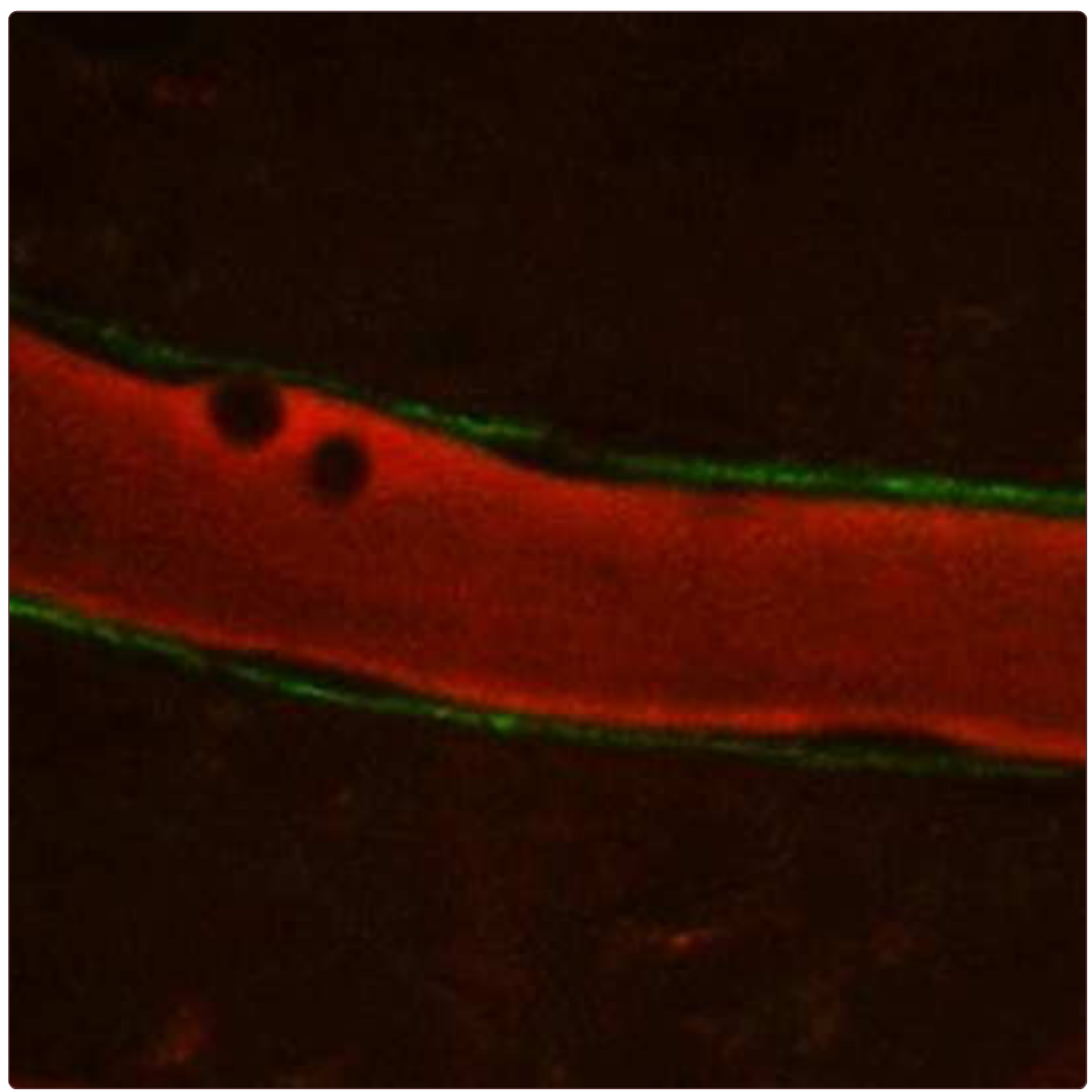

Syndecan-1 (CD138) deficiency increases Staphylococcus aureus infection but has no effect on pathology in a mouse model of peritoneal dialysis

Kowalewska et al. 


\title{
Syndecan-1 (CD138) deficiency increases Staphylococcus aureus infection but has no effect on pathology in a mouse model of peritoneal dialysis
}

\author{
Paulina M. Kowalewska', Uyen T. Nguyen², Lori L. Burrows ${ }^{2}$ and Alison E. Fox-Robichaud ${ }^{1,3^{*}}$
}

\begin{abstract}
Background: Technique failure in peritoneal dialysis (PD) due to fibrosis and angiogenesis is complicated by peritonitis. Staphylococcus aureus infection is one of the most common causes of peritonitis in PD. The heparan sulfate proteoglycan, syndecan-1 (CD138), was reported to regulate fibrosis, angiogenesis, inflammation and S. aureus infection. The objectives of this study were to examine the effects of syndecan-1 on S. aureus infection and histopathology in a PD model.
\end{abstract}

Results: Syndecan-1 $1^{-/-}$and wild type mice were dialyzed for 4 weeks and infected intraperitoneally with S. aureus. Tissues were collected after $4 \mathrm{~h}$ for histomorphometric analysis. Intravital microscopy was used to observe leukocyte recruitment and to quantify syndecan-1 in the parietal peritoneum microcirculation. The dialyzed syndecan-1 $1^{-1-}$ mice were more susceptible to $S$. aureus infection than undialyzed syndecan-1 $1^{-/}$controls and wild type animals. However, peritoneal fibrosis and neovascularization due to PD did not differ between syndecan- $1^{-1}$ and wild type mice. Intravital microscopy showed that in S. aureus infection, syndecan-1 was removed from the subendothelial layer of peritoneal venules but syndecan-1 deficiency did not affect leukocyte recruitment.

Conclusions: This study indicates that, while syndecan-1 is important for providing a barrier to acute $S$. aureus infection in PD, it does not affect peritoneal fibrosis and angiogenesis.

Keywords: Intravital microscopy, Leukocyte recruitment, Microcirculation, Fibrosis, Peritonitis, Proteoglycans

\section{Background}

Peritoneal dialysis (PD) is an effective replacement therapy for chronic kidney failure. In PD, dialysis solution is administered into the peritoneal cavity through a surgically implanted catheter and there is an exchange of water and solutes between the patient's blood and the indwelling solution across the peritoneal membrane, allowing for removal of excess water and wastes. However, PD failure typically occurs because of infection or loss of ultrafiltration [1-3]. Underlying the loss of ultrafiltration are deleterious alterations of the peritoneum

\footnotetext{
* Correspondence: afoxrob@mcmaster.ca

${ }^{1}$ Thrombosis and Atherosclerosis Research Institute and the Department of Medicine, McMaster University, Hamilton, ON, Canada

${ }^{3}$ David Braley Cardiac, Vascular and Stroke Research Institute, C5-106, 237

Barton Street East, Hamilton, ON L8L 2X2, Canada

Full list of author information is available at the end of the article
}

involving progressive fibrosis, angiogenesis, vasculopathy, and phenotypic change of mesothelial cells of the peritoneal membrane [4-6] to a fibroblast-like state, a process referred to as epithelial-mesenchymal transition (EMT). These deleterious alterations are further complicated by bacterial peritonitis. The main site of infection in PD is the lumen of the catheter from touchcontamination as well as the outside of the catheter at the exit site. Staphylococcus aureus, Staphylococcus epidermidis, Pseudomonas aeruginosa and Escherichia coli are among the most common microorganisms causing peritonitis in PD [7-9].

The cell surface heparan sulfate proteoglycan, syndecan1 (Sdc1; CD138), modulates diverse processes such as inflammation [10], wound repair [11], angiogenesis [12], fibrosis [13], and EMT [14, 15]. Syndecan-1 is a single- 
pass type I transmembrane protein with several heparan sulfate glycosaminoglycan chains covalently attached to the distal portion of the extracellular domain. Syndecan-1 is expressed on mesothelial cells of the parietal peritoneum, and in the subendothelial compartment of peritoneal venules [16]. Some microbial pathogens subvert syndecan1 to increase dissemination and host defense evasion during infection. Among the best-characterized pathogens that manipulate syndecan-1 is $S$. aureus [17]. Although the role of certain proteoglycans was examined in dialysis [18], the role of syndecan-1 has not been investigated in PD. Given that syndecan-1 regulates inflammation, fibrosis, angiogenesis and EMT, and syndecan-1-microbial interactions are important in the pathogenesis of $S$. aureus, the aims of this study were to characterize the effects of syndecan-1 deficiency on peritoneal histopathology, foreign body reaction, and $S$. aureus infection during subacute (4 weeks) PD. In addition, we examined the effects of acute $S$. aureus infection on syndecan-1 protein expression in the peritoneal microcirculation and its role in leukocyte recruitment.

\section{Methods}

\section{Animals}

The animal protocols met the regulations set by the Canadian Council of Animal Care and were approved by the McMaster University Animal Research Ethics Board (Animal Utilization Protocol \#11-01-03). All animal protocols followed the "Animal research: reporting of in vivo experiments" guidelines [19]. Six- to 8-weekold male BALB/c mice were obtained from Taconic (Germantown, NY, USA) and given at least 1 week to acclimatize in a specific pathogen-free facility. These mice were verified to be $S$. aureus-free by the supplier. The age-matched syndecan-1 null $\left(S d c 1^{-1-}\right)$ male mice used in this study were on a BALB/c background and sourced from a colony that was interbred and maintained at McMaster University Central Animal Facility. The $S d c 1^{-1-}$ breeders, which tested negative for $S$. aureus, were a kind gift from Dr. Pyong W. Park (Children's Hospital, Harvard Medical School, Boston, MA, USA). Syndecan-1 deficiency in the mouse colony was confirmed using in vivo imaging of the parietal peritoneum microcirculation with immunofluorescence [16].

\section{Nonuremic subacute peritoneal dialysis model}

Detailed methods were previously described [20]. Sterile silicone catheters (inner diameter (ID) $0.635 \mathrm{~mm}$, outer diameter (OD) $1.1938 \mathrm{~mm}$ ) attached to silicone injection ports (Penny MousePort ${ }^{\mathrm{m}}$; Access Technologies, Skokie, IL, USA) were aseptically implanted subcutaneously into wild type and $S d c 1^{-1-}$ mice under gaseous anesthesia. Before insertion, the port and catheter were flushed with $10 \%$ heparin (1000 USP Units $\mathrm{mL}^{-1}$; Sandoz Canada
Inc., Boucherville, QC, Canada) to maintain patency. The 1-cm tip of the catheter was inserted through the right lower quadrant of the abdominal wall into the peritoneal cavity. One week after catheter implantation, $10 \%$ heparin solution was injected into the port to keep the catheter patent. The mice were given 2 weeks to acclimatize to the implant. After the acclimatization period, daily 2-mL injections of a conventional lactatebuffered dialysis solution (Dianeal PD4 CAPD Solution with $2.5 \%[\mathrm{w} / \mathrm{v}]$ dextrose and $2.5 \mathrm{mEq} \mathrm{L}^{-1}$ calcium, approximate $\mathrm{pH}$ 5.2; Baxter, Mississauga, ON, Canada) were administered into the Penny MousePort ${ }^{\mathrm{m}}$ for 4 weeks. The skin over the port was sterilized and injections were performed using aseptic technique in a biological safety cabinet.

\section{Bacterial strain and growth conditions}

S. aureus H1559 cultures were grown overnight on a shaker in tryptic soy broth (TSB) (EMD, Darmstadt, Germany) plus $15 \mu \mathrm{g} \mathrm{mL}{ }^{-1}$ of erythromycin (Sigma-Aldrich $^{\circ}$, St. Louis, MO, USA) to select for a green fluorescent protein (GFP)-expressing plasmid, constitutively expressed from the prsA promoter cloned into pCN56 [21]. The overnight cultures were diluted 100 -fold in fresh TSB and grown for $2.5 \mathrm{~h}$ at $37{ }^{\circ} \mathrm{C}$ to an optical density of $\sim 0.5$ at $600 \mathrm{~nm}$. The subcultures were sedimented, washed and suspended in $100 \mu \mathrm{L}$ of sterile $1 \mathrm{X}$ phosphate-buffered saline (PBS; pH 7.2, $0.14 \mathrm{M} \mathrm{NaCl}$, $2.7 \mathrm{mM} \mathrm{KCl}, 0.88 \mathrm{mM} \mathrm{KH} \mathrm{PO}_{4}, 6.4 \mathrm{mM} \mathrm{Na} 2 \mathrm{HPO}_{4}$. $7 \mathrm{H}_{2} \mathrm{O}$ ). Colony-forming units (CFU) were enumerated following serial dilutions and plating on tryptic soy agar (TSA) plates with $10 \mu \mathrm{g} \mathrm{mL}^{-1}$ erythromycin (Teknova, Hollister, CA, USA). The inocula contained approximately $1.8 \times 10^{8} \mathrm{CFU}$.

\section{S. aureus infection and tissue collection}

On the last day of the 4-week dialysis period, mice received an injection of $S$. aureus into the subcutaneous port, which was immediately followed by an injection of $2 \mathrm{~mL}$ of dialysis solution through the port. The infected non-PD controls were wild type and $S d c 1^{-1-}$ animals that did not undergo dialysis and were injected intraperitoneally (IP) on the right side with an equivalent amount of S. aureus suspension. After $4 \mathrm{~h}$, wild type and $S d c 1^{-1}$ mice were anesthetized with a subcutaneous injection of a mixture of ketamine $\left(200 \mathrm{mg} \mathrm{kg}^{-1}\right)$ and xylazine (10 $\mathrm{mg} \mathrm{kg}^{-1}$ ). Under sterile conditions, peritoneal lavage was performed with $2 \mathrm{~mL}$ of PBS. The intra-abdominal portion of the PD catheter was retrieved and fixed in $2 \%$ [v/v] glutaraldehyde in sodium cacodylate. Samples of the anterior abdominal wall from dialyzed animals were collected in a standardized manner from the left upper quadrant, adjacent to the midline and contralateral to the catheter insertion site. This position was above the 
region that contacted the intra-abdominal catheter tip. For the undialyzed animals that received a suspension of $S$. aureus with an IP needle injection, the section of abdominal wall sampled was contralateral and superior to the injection site. Anatomically matching areas were extracted for baseline histology. The samples were fixed in $10 \%[\mathrm{v} / \mathrm{v}]$ buffered formalin. Additional samples of the anterior abdominal wall, taken from the left lower quadrant, were homogenized. Blood was collected via cardiac puncture. Euthanasia was ensured by cervical dislocation.

Colony-forming units from the peritoneal lavage fluid, blood and abdominal wall homogenate were enumerated after serial dilutions and plating on TSA plates with 10 $\mu \mathrm{g} \mathrm{mL}{ }^{-1}$ erythromycin. The peritoneal lavage fluid and blood were mixed with $3 \%[\mathrm{v} / \mathrm{v}]$ acetic acid (Caledon Laboratory Chemicals, Georgetown, ON, Canada) and $1 \%[\mathrm{w} / \mathrm{v}]$ crystal violet (Sigma-Aldrich ${ }^{\circ}$ ) in a 5:44:1 ratio. Blood cell counts with a hemacytometer were averaged from 6 separate samples of the mixture of blood or lavage fluid. Differential white blood cell counts were performed on smears of blood fixed in methanol and stained with eosin and thiazine (Harleco Hemacolor ${ }^{\circ}$ stain set; EMD Chemicals, Gibbstown, NJ, USA). Results were compared with baseline levels in wild type and $S d c 1^{-1-}$ mice that did not undergo PD and were not infected. In total, 6 groups were observed, with $n=8$ mice in the wild type and $S d c 1^{-1-}$ baseline groups as well as the $S d c 1^{-1-}$ infected non-PD group and $S d c 1^{-1-}$ infected PD group. The wild type infected non-PD and infected PD groups both had 14 mice.

\section{Scanning electron microscopy}

The catheter pieces were immersed for $2 \mathrm{~h}$ in primary fixative solution $(2 \%[\mathrm{v} / \mathrm{v}]$ glutaraldehyde in $0.1 \mathrm{M}$ sodium cacodylate buffer at $\mathrm{pH}$ 7.4). The samples were rinsed twice in buffer solution and post-fixed for $1 \mathrm{~h}$ in $1 \%[\mathrm{w} / \mathrm{v}]$ osmium tetroxide in $0.1 \mathrm{M}$ sodium cacodylate buffer. After the second fixation step, the samples were dehydrated through a graded ethanol series and then dried in a critical point dryer. After drying, the catheter pieces were cut open to expose the inner surface of the catheters and mounted onto scanning electron microscopy stubs. The stubs were sputter coated with gold and viewed with a Tescan Vega II LSU scanning electron microscope (Tescan USA, Cranberry TWP, PA, USA) operating at $20 \mathrm{kV}$. Image acquisition was performed with Tescan VegaTC operating software (Tescan USA, Cranberry TWP, PA, USA).

\section{Histopathologic examination}

The formalin-fixed tissue samples were embedded in paraffin and thin-sectioned. The cross-sections were stained with hematoxylin and eosin (H\&E) (Sigma-Aldrich ${ }^{\circ}$ ) or picro-sirius red (abcam ${ }^{\circ}$, Cambridge, MA, USA) for visualization of collagen. For identification of elastic fibers, cross-sections were stained with resorcin-fuchsin and counterstained in van Gieson's solution and Weigert's iron hematoxylin (Electron Microscopy Sciences, Hatfield, PA, USA). Microscopic examination was performed using an Olympus BX41 microscope with an Olympus DP72 ${ }^{\circ}$ camera (Olympus America Inc., Center Valley, PA, USA) and acquired using SlideBook 5.0 custom-built microscopy software (Intelligent Imaging Innovations, Inc., Denver, Co, USA). Peritoneal thickness was measured at five random locations in each H\&E-stained section and averaged, and the number of peritoneum-associated blood vessels was counted along the entire length of the section of peritoneum and recorded as vessels per $\mathrm{mm}$ of peritoneum. The blood vessel counts were verified using immunohistochemical staining of the paraffin-embedded tissues with a monoclonal antibody to the cell surface marker platelet endothelial cell adhesion molecule-1 (PECAM-1; CD31).

\section{Immunohistochemistry}

Paraffin sections were placed on a slide and deparaffinised, hydrated and heated in citrate buffer in preparation for immunohistochemistry (IHC). After quenching endogenous peroxidase activity and blocking with normal goat serum, the sections were incubated with rat anti-mouse F4/80 monoclonal antibody (clone CI:A3-1; Santa Cruz Biotechnology, Inc., Dallas, Texas, USA) or isotype control antibody (rat IgG2b, clone 141945; R\&D Systems ${ }^{\circ}$, Inc., Minneapolis, MN, USA) for $48 \mathrm{~h}$ at $4{ }^{\circ} \mathrm{C}$. Biotinylated goat anti-rat secondary antibody was used to detect the primary antibody and visualized using the $\mathrm{ABC}$ system with 3,3'-diaminobenzidine (DAB) as the chromogen (ImmunoCruz ${ }^{\text {tm }}$ Rat ABC Staining System; Santa Cruz Biotechnology, Inc.). The sections were counterstained with Gill's hematoxylin solution No. 2 (Santa Cruz Biotechnology, Inc.). Microscopic examination of macrophages in the peritoneal tissue was performed using an Olympus BX41 microscope. The ImmunoCruz ${ }^{\mathrm{Tm}}$ Rat ABC Staining System was also used for immunohistochemical staining of blood vessels using rat anti-mouse PECAM-1/CD31 monoclonal antibody (clone RM00321D12; Santa Cruz Biotechnology, Inc.).

\section{Preparation for intravital microscopy}

For all intravital microscopy (IVM) experiments, a new set of animals was used that was not treated with PD. The detailed methods on the surgical preparation for IVM were previously described [16]. Briefly, animals were anesthetized (ketamine and xylazine) and the right internal jugular vein was cannulated with a polyethylene catheter (ID $0.28 \mathrm{~mm}$, OD $0.61 \mathrm{~mm}$, Intramedic ${ }^{\mathrm{Tw}}$, Becton, Dickinson and Company, Mississauga, ON, Canada) for maintenance of anesthesia, administration 
of fluids or fluorescent antibodies. Skin was bluntly dissected away and a midline incision along the linea alba was made in the abdominal wall extending inferiorly from the xiphoid process towards the left inguinal region. The animals were placed in the right lateral position and the peritoneum on the left side of the abdominal wall was laid out on a microscope stage and covered with plastic wrap to prevent evaporative loss.

\section{Spinning disk confocal intravital microscopy}

Wild type mice were injected IP with S. aureus lipoteichoic acid (LTA) $\left(125 \mu \mathrm{g}\right.$; Sigma-Aldrich $\left.{ }^{\circ}\right)$ or a $100 \mu \mathrm{L}$ suspension of GFP-expressing S. aureus cells containing approximately $1.8 \times 10^{8} \mathrm{CFU}(n=4$ mice). After $4 \mathrm{~h}$, the mice were prepared for IVM of the parietal peritoneum microcirculation and injected intravenously (IV) with Alexa Fluor ${ }^{\circ}$ 568-labeled rat anti-mouse syndecan-1 ectodomain antibody (40 $\mu \mathrm{g}$, clone 300506; R\&D Systems ${ }^{\circ}$, Inc.). The peritoneal microcirculation was visualized with a spinning disc confocal system (Leica DMI 6000 B; Leica Microsystems, Mannheim, Germany) based on a Yokogawa spinning disc confocal unit, spectral laser merge module LMM5, and Hamamatsu back-thinned electron multiplying charge-coupled device C9100-12 camera (Hamamatsu, Hamamatsu City, Japan). During the IVM observations, the animals were placed in a chamber mounted on the confocal microscope and the temperature in the chamber was set to $37^{\circ} \mathrm{C}$. The peritoneal microcirculation was observed with a $40 \times$ objective lens and images were acquired using the Volocity $^{\circ} 4$ acquisition software (Improvision, Waltham, MA, USA).

\section{Quantification of fluorescence intensity}

Using ImageJ (National Institutes of Health, W. Rasband, Bethesda, Maryland, USA), the fluorescence intensity of the Alexa Fluor ${ }^{\circ}$ 568-conjugated anti-syndecan-1 antibodies was quantified from the captured in vivo images of peritoneal venules. The fluorescence intensity of the labeled antibodies was measured along the length of the basolateral side of the venular endothelium and the value for the corresponding intravascular fluorescence intensity was subtracted. This relative difference in intensity was calculated for 4 venules per mouse and the values were recorded as the difference in mean fluorescence intensity (arbitrary fluorescence units).

\section{Transillumination intravital microscopy}

Wild type and $S d c 1^{-1-}$ mice were injected IP with approximately $1.8 \times 10^{8} \mathrm{CFU}$ of $S$. aureus $(100 \mu \mathrm{L})$, while clinical grade saline $(0.9 \%[\mathrm{w} / \mathrm{v}] \mathrm{NaCl})$ was injected IP into control animals $(n=4$ mice). All IP injections were performed on the right side. The microcirculation underlying the parietal peritoneum on the left side of the abdominal wall was observed using an inverted intravital microscope (Zeiss Inverted Axiovert 100; Carl Zeiss, Jena, Germany). The tissue was transilluminated with a light source via fiberoptic (The $\mathrm{ACE}^{\bullet}$ Series; Schott-Fostec, LLC, Auburn, NY, USA) equipped with a 150 Watt tungsten halogen lamp. Images were captured with an attached camera (Newvicon; DAGE-MTI, Michigan City, IN, USA), projected onto a monitor (Panasonic, CT-2086YD; Panasonic Canada Inc., Mississauga, ON, Canada) and recorded with a DVD recorder (Panasonic, DMR-EH55) for offline analysis. The animals were warmed with an infrared heat lamp positioned over the microscope during the intravital observations. To minimize effects of tissue exposure during IVM [22], observations were made within $10 \mathrm{~min}$ after completion of surgical preparation. Euthanasia was performed by cervical dislocation under deep anesthesia.

\section{Offline analysis}

Leukocyte-endothelial cell interactions were quantified in 4-6 venules per mouse. Rolling leukocytes, considered as cells tethering to a venule with torsional motion, were counted per minute. Intravascular leukocytes that remained stationary for at least $30 \mathrm{~s}$ were identified as adherent cells and perivenular leukocytes were counted as extravascular cells on a field of view measuring 180 $\mu \mathrm{m} \times 135 \mu \mathrm{m}$.

\section{Statistical analysis}

Data are expressed as mean \pm standard error of the mean (SEM). Statistical significance was set at $p<0.05$ and calculated using Student's $t$-test or ANOVA with Bonferroni correction using the computer software package KaleidaGraph 3.6 (Synergy Software, Reading, PA, USA).

\section{Results \\ Animal characteristics}

Following catheter implantation surgery, there were no significant changes in behavior or appearance of the animals and skin incisions healed well, with no signs of infection. One mouse in the $S d c 1^{-1-}$ group was euthanized at the end of the catheter acclimatization period because of fighting injuries from the cage mate. There were no differences in the weights of the animals between the wild type group and $S d c 1^{-1-}$ group at the start $(26.93 \pm$ $0.30 \mathrm{~g}$ versus $25.88 \pm 0.55 \mathrm{~g}$, respectively) and end $(30.50 \pm 0.42 \mathrm{~g}$ versus $29.13 \pm 0.44 \mathrm{~g}$, respectively) of the experiment. Upon midline laparotomy, $1 / 14$ wild type mice had omental wrapping of the catheter at the entry site on the abdominal wall, and 8/14 wild type mice and 5/8 Sdc1 ${ }^{-1-}$ mice had gonadal adipose tissue wrapping at catheter entry site with no occlusion of the catheter tip. 
$S d c 1^{-/-}$mice have higher S. aureus loads in the abdominal wall after peritoneal dialysis

To determine whether subacute exposure to PD and lack of syndecan-1 affect the progression of $S$. aureus peritoneal infection, wild type and $S d c 1^{-/-}$mice were infected through the peritoneal catheter, while control animals were infected through a needle injection IP. Four hours post-infection, peritoneal lavage fluid, blood and a sample of the left abdominal wall were collected for CFU enumeration. There were no significant differences in the CFU counts from the peritoneal lavage between dialyzed animals and non-dialysis controls, or wild type and $S d c 1^{-1-}$ mice (Fig. 1a). There were also no differences in CFU counts from blood samples between any of the groups (Fig. 1b). An outlier was excluded from the $S d c 1^{-1-}$ PD group because the value was far beyond the range of values calculated by subtraction and addition of 1.5 times the interquartile range to the first and third quartile. Contamination during cardiac puncture was strongly suspected. Nevertheless, ANOVA tests with Bonferroni correction did not show any significant difference between the groups with and without the inclusion of the outlier. The bacterial counts from the blood suggested sepsis in some animals, which was accompanied by diarrhea and slower movement. The CFU counts from the abdominal wall homogenate samples were significantly increased in the $S d c 1^{-/-}$animals, but only in the group that was treated with PD (Fig. 1c). These results indicate that the parietal peritoneum and the underlying tissues of $S d c 1^{-/-}$mice are more susceptible to $S$. aureus invasion in the context of PD-induced injury.

All of the infected animals had a significantly increased number of peritoneal leukocytes compared with baseline levels (Table 1). Although the peritoneal leukocyte counts were reduced in the $S d c 1^{-1-}$ animals with $S$. aureus infection compared with wild type, the difference was not statistically significant. Systemic white blood cell counts did not significantly differ between the groups; however, the number of systemic neutrophils was significantly decreased in the dialyzed wild type animals compared with non-PD controls. Also, the number of systemic monocytes was significantly elevated in wild type non-PD animals with $S$. aureus infection compared with $S d c 1^{-1-}$ mice and baseline controls.

\section{Host material deposition in the peritoneal catheters of} $S d c 1^{-/-}$and wild type mice

Foreign body reactions are characterized by macrophage adherence to implants and fusion to form foreign body giant cells [23]. In vitro work showed that $S d c 1^{-1-}$ macrophages have impaired motility [24]. Thus, foreign body reactions to the catheter implant were examined using scanning electron microscopy after $4 \mathrm{~h}$ of $S$. aureus
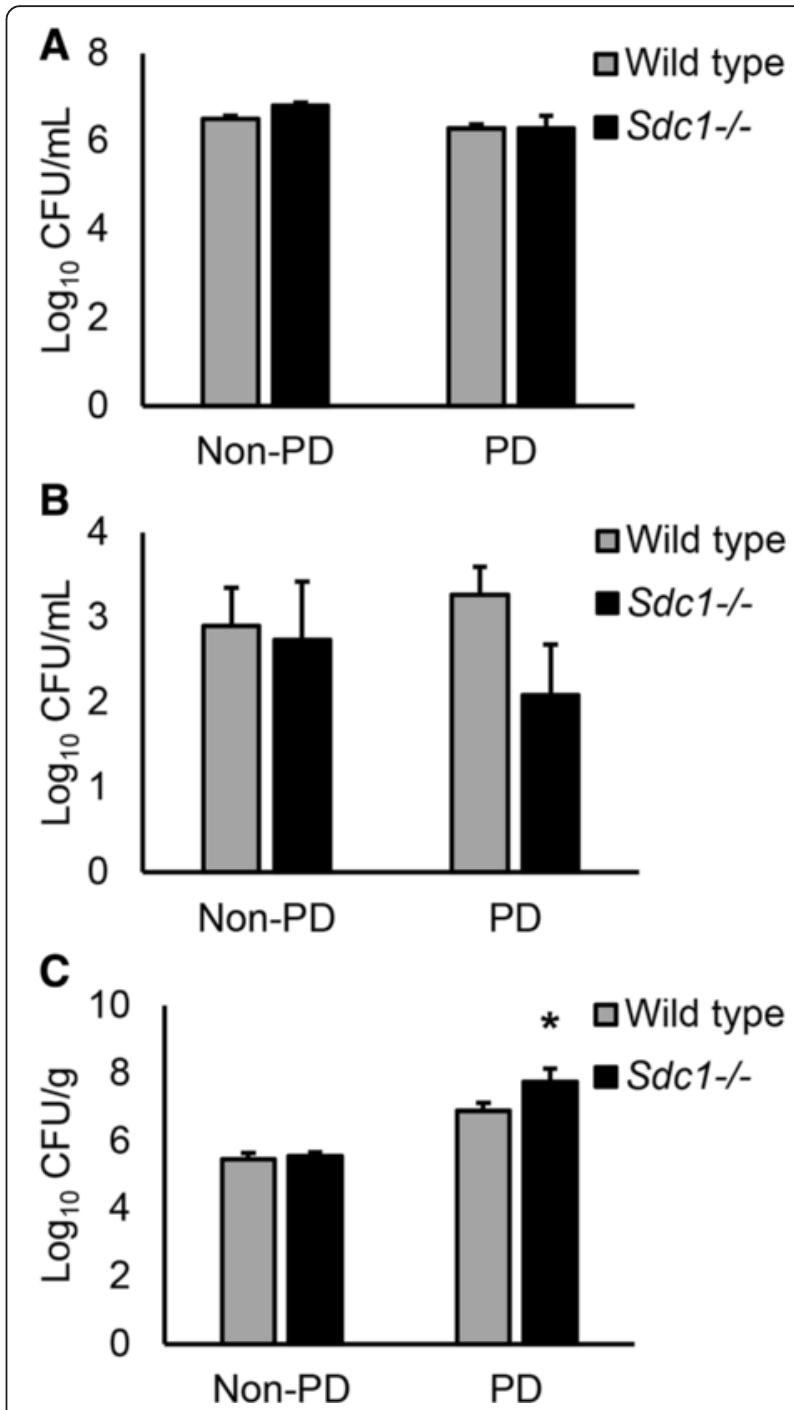

Fig. $1 \mathrm{Sdcl}^{-1-}$ mice have higher S. aureus loads in the abdominal wall after peritoneal dialysis (PD). Viable bacteria counts from (a) lavage samples, (b) blood and (c) abdominal wall homogenates from wild type and $\mathrm{Sdcl}^{-1-}$ mice collected $4 \mathrm{~h}$ after the animals were injected with $1.8 \times 10^{8}$ colony-forming units (CFU) of S. aureus through the peritoneal catheter (PD group) or with an intraperitoneal needle injection (non-PD group). Data recorded as mean \pm SEM, analyzed with ANOVA with Bonferroni correction and expressed as $\log _{10}$ CFU per $\mathrm{mL}$ of peritoneal fluid or blood, or $\mathrm{g}$ of tissue, $n=14$ mice in the wild type infected non-PD group and wild type PD group, $n=8$ mice in all other groups, ${ }^{*} p<0.01$ compared with all other groups. $\mathrm{Sdcl}^{-1-}$ mice that were dialyzed for 4 weeks had a significantly higher number of viable bacterial cells in the abdominal wall samples after $4 \mathrm{~h}$ of infection

infection. Leukocytes, platelets and crenated red blood cells were recruited to the catheter lumen (Fig. 2a). Leukocytes reacted to the foreign body by attachment to the surface within a fibrin network (Fig. 2b). These included macrophages and neutrophils that appeared to communicate through cell surface extensions. The inflammatory cells interacted with $S$. aureus microcolonies 
Table 1 Peritoneal lavage leukocyte counts and differential blood leukocyte counts

\begin{tabular}{lccccc}
\hline Treatment/strain & Total peritoneal cells $\times 10^{6}$ & Total blood cells $\times 10^{9} \mathrm{~L}^{-1}$ & Blood neutrophils & Blood lymphocytes & Blood monocytes \\
\hline Baseline wild type & $3.52 \pm 0.43$ & $4.08 \pm 0.67$ & $0.99 \pm 0.27$ & $3.06 \pm 0.42$ & $0.04 \pm 0.01^{* *}$ \\
Baseline Sdc1- & $2.78 \pm 0.28$ & $4.56 \pm 0.68$ & $1.14 \pm 0.26$ & $3.40 \pm 0.51$ & $0.02 \pm 0.01$ \\
Non-PD + S. aureus wild type & $25.78 \pm 3.43^{* * *}$ & $4.98 \pm 0.65$ & $1.80 \pm 0.20$ & $3.14 \pm 0.53$ & $0.34 \pm 0.07$ \\
Non-PD + S. aureus Sdc1 $1^{--}$ & $15.94 \pm 1.57^{* * *}$ & $3.62 \pm 0.49$ & $1.58 \pm 0.31$ & $2.01 \pm 0.25$ & $0.03 \pm 0.02^{* *}$ \\
PD + S. aureus wild type & $31.65 \pm 1.90^{* * *}$ & $3.12 \pm 0.33$ & $0.79 \pm 0.12^{*}$ & $2.14 \pm 0.27$ & $0.19 \pm 0.04$ \\
PD + S. aureus Sdc1- & $22.42 \pm 1.89^{* * *}$ & $3.29 \pm 0.52$ & $1.05 \pm 0.16$ & $2.11 \pm 0.41$ & $0.13 \pm 0.03$ \\
\hline
\end{tabular}

At the end of the peritoneal dialysis (PD) period, mice were infected intraperitoneally with $1.8 \times 10^{8}$ colony-forming units of $S$. aureus and $4 \mathrm{~h}$ after, peritoneal lavage was performed and blood was collected via cardiac puncture for enumeration of leukocytes. Data recorded as mean \pm SEM and analyzed with ANOVA with Bonferroni correction, 6 counts averaged per mouse, $n=8-14$ mice, ${ }^{*} p<0.01$ and ${ }^{* *} p<0.001$ compared with non-PD wild type infected mice, ${ }^{* * *} p<0.0001$ compared with baseline values. S. aureus-infected mice had significantly increased numbers of peritoneal leukocytes compared with baseline but systemic leukocyte counts did not differ significantly

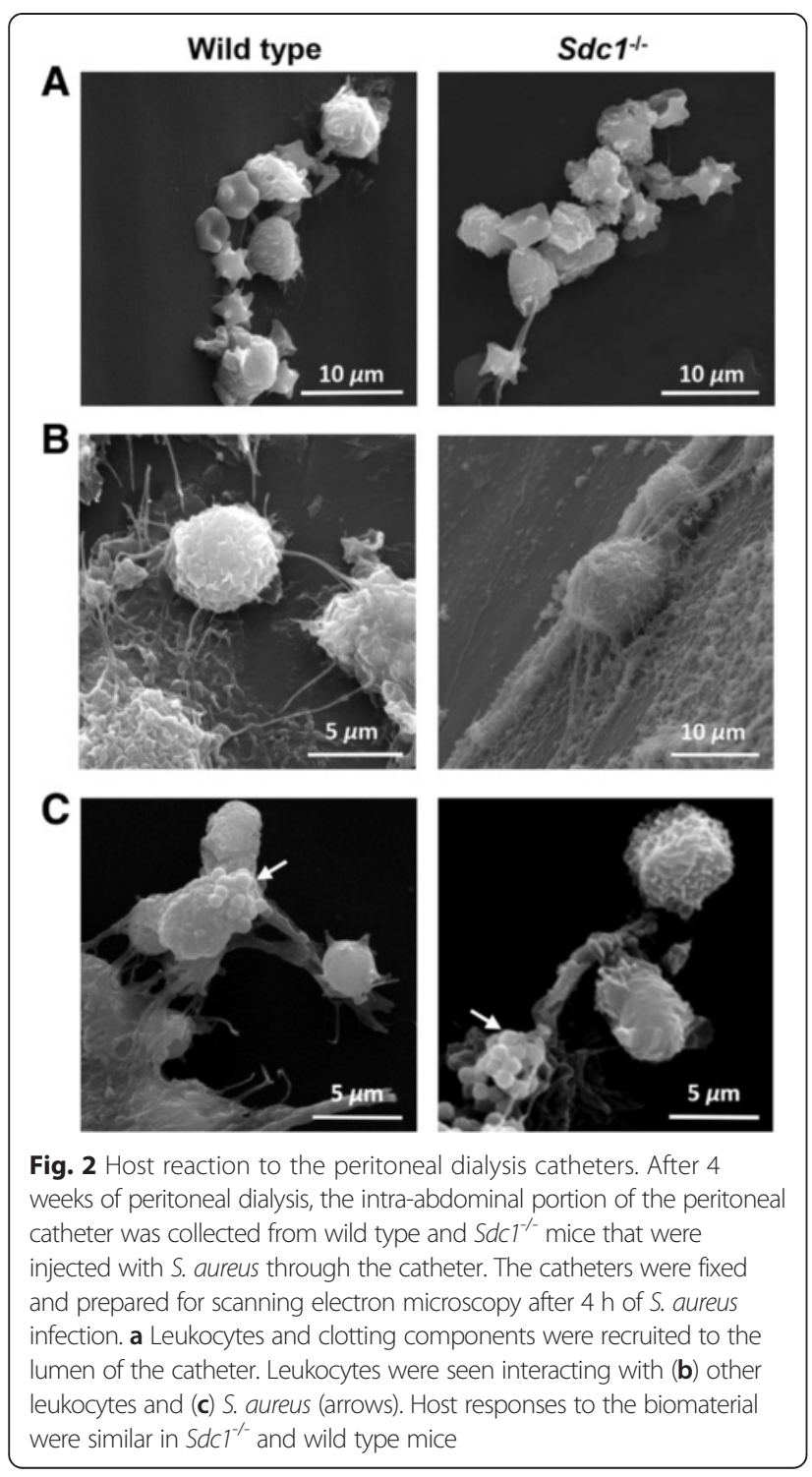

(Fig. 2c). The results suggest that syndecan-1 deficiency does not alter the recruitment of inflammatory cells to a foreign body.

\section{Syndecan-1 deficiency does not affect histopathologic} changes of the peritoneum in subacute peritoneal dialysis Baseline control animals had an intact mesothelial surface (Fig. 3a) and non-PD mice that received an IP injection of $S$. aureus did not exhibit mesothelial disruption (Fig. 3b). Mice that were treated with PD, however, had a thickened peritoneum, with increased vascularization, interstitial hypercellularity, and leukocyte infiltration (Fig. 3c). The average thickness of the peritoneal layer was significantly increased in the PD groups (Fig. 4a), which suggests fibrosis. However, there was no significant difference between $S d c 1^{-1-}$ mice and wild type animals. The number of peritoneum-associated vessels was significantly increased in dialyzed animals compared with non-PD controls but did not differ between the $S d c 1^{-1-}$ mice and wild type animals (Fig. $4 \mathrm{~b}$ ). These blood vessel counts were verified with immunohistochemicallystained paraffin sections with anti-PECAM-1/CD31 and were found to be similar between the two methods (data not shown). Increased collagen deposition is characteristic of fibrosis. Extensive and disorganized collagen deposition was observed in the thickened peritoneal layer of dialyzed animals (Fig. 5) in both wild type and $S d c 1^{-1-}$ mice. While the submesothelial layer of elastic fibers was near the mesothelial surface in undialyzed animals (Fig. 6a), it was several cell layers below the surface in the dialyzed wild type and $S d c 1^{-1-}$ mice (Fig. 6b-d). Macrophages are a source of profibrotic molecules [25]. In the parietal peritoneum, depletion of macrophages was associated with decreased fibrosis in a mouse model of PD [26]. Thus, the presence of macrophages in the fibrotic peritoneal tissue was detected with IHC using F4/80, a cell surface marker for mature macrophages in mice. With the immunohistochemical analysis, $\mathrm{F} 4 / 80^{+}$cells were not detected in the infected non-PD control animals, but were found to be concentrated near the peritoneal surface in the dialyzed 


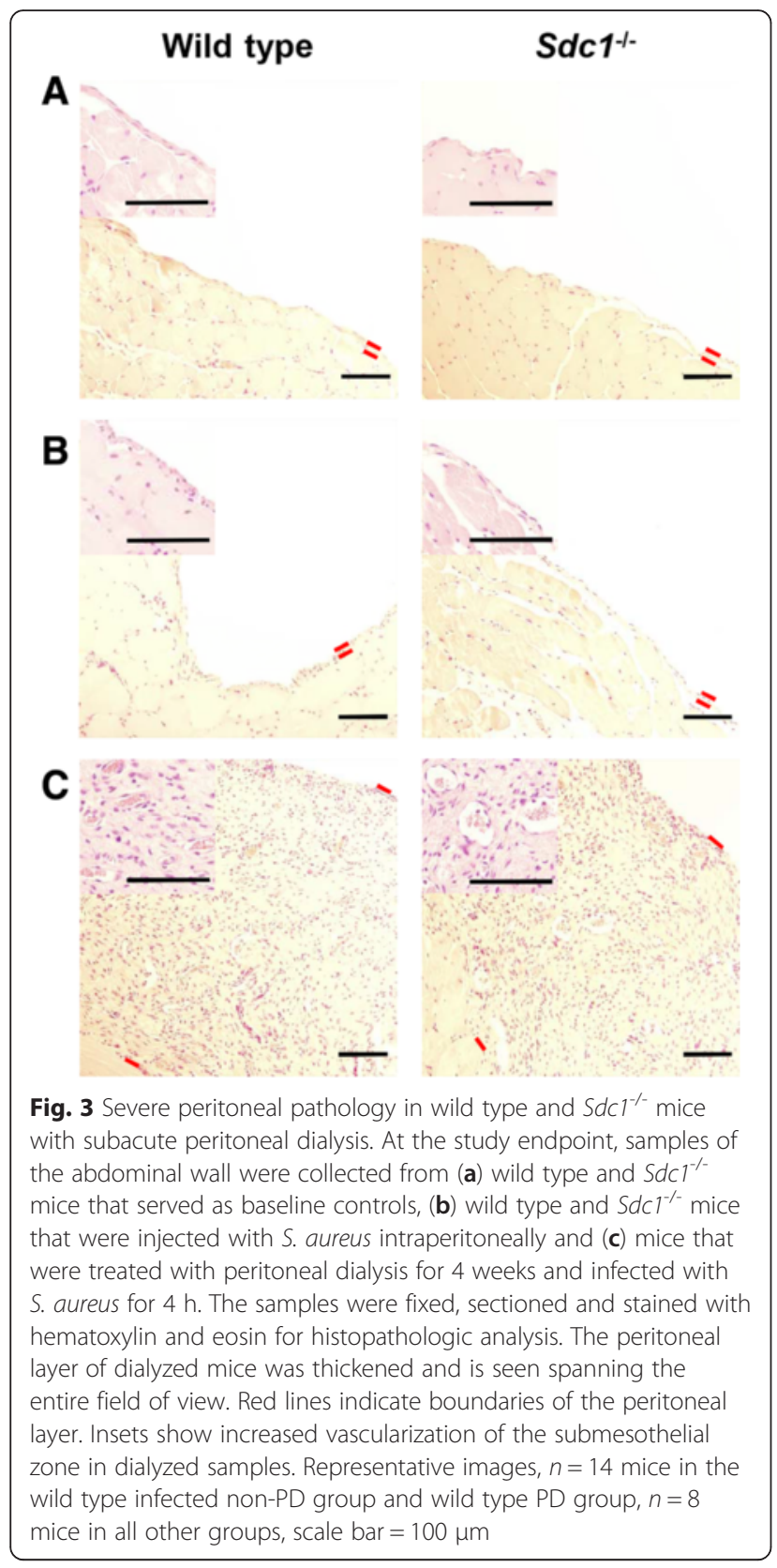

wild type and $S d c 1^{-1-}$ animals in some areas of the sections (Fig. 7a). The adjacent sections that were incubated with the isotype control antibodies had no significant background signal (Fig. 7b). Taken together, these findings suggest that syndecan-1 is not a major modulator of morphological changes due to fibrosis and angiogenesis in PD-induced histopathology.

\section{S. aureus infection decreases subendothelial syndecan-1 in the peritoneal venules}

To examine the effects of $S$. aureus infection on syndecan-1 levels in the peritoneal microcirculation, fluorescence IVM was performed on wild type mice that

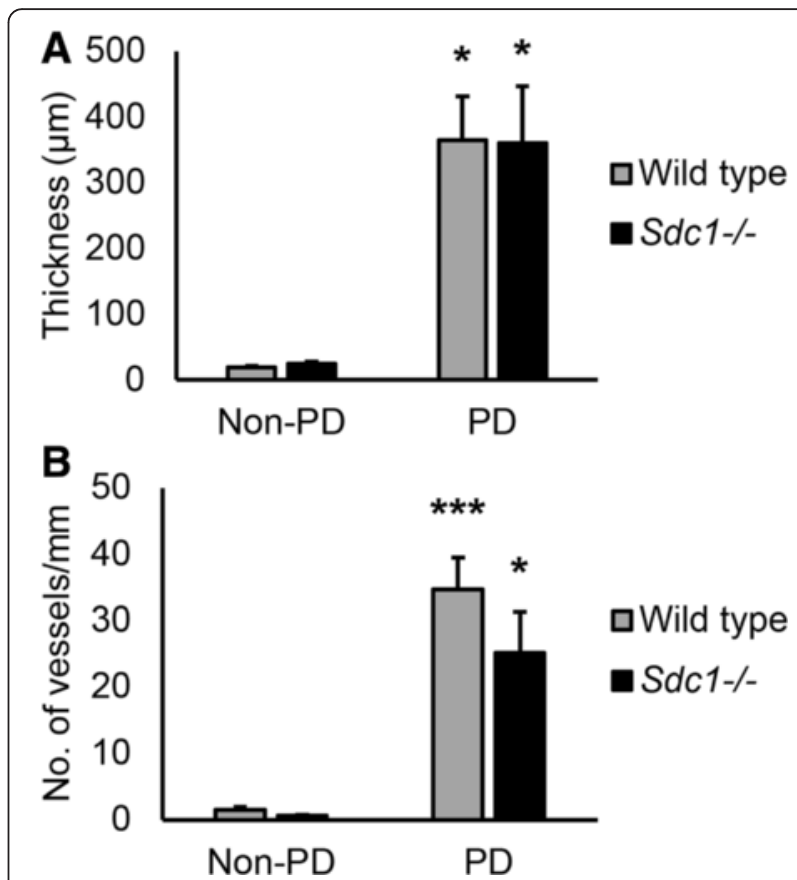

Fig. 4 Wild type and $\mathrm{SdCl}^{-1-}$ mice exhibit similar levels of fibrosis and neovascularization during subacute peritoneal dialysis (PD). The (a) thickness and (b) vascular density of the peritoneal layer were quantified from the hematoxylin and eosin-stained sections. Data recorded as mean \pm SEM and analyzed with ANOVA with Bonferroni correction, $n=14$ mice in the wild type groups and $n=8$ mice in the $\mathrm{Sdcl}^{-1-}$ groups, ${ }^{*} p<0.01$ and ${ }^{* * *} p<0.0001$ compared with controls that were not treated with peritoneal dialysis (non-PD).

There were no differences in the levels of fibrosis and vascularization in the peritoneal layer of wild type and $\mathrm{SdCl}^{-1-}$ mice

were injected IP with $S$. aureus LTA or GFP-expressing $S$. aureus and, after $4 \mathrm{~h}$, the mice were injected IV with Alexa Fluor ${ }^{\circ}$ 568-labeled anti-syndecan-1. During LTAinduced sterile inflammation, anti-syndecan-1 was detected on the subendothelial side of peritoneal venules (Fig. 8a). With S. aureus infection, however, anti-syndecan1 antibody did not label peritoneal venules (Fig. 8b), as shown by quantification of fluorescence intensity from the anti-syndecan-1 antibodies on venules in LTA-injected and $S$. aureus-infected mice (Fig. 8c). The GFP-expressing $S$. aureus cells were not visible against the tissue background (Fig. 8b). These findings indicate that $S$. aureus infection decreased syndecan-1 protein levels in the subendothelial region of peritoneal venules.

Syndecan-1 does not modulate leukocyte recruitment to the parietal peritoneum microcirculation during $S$. aureus infection

To investigate whether syndecan-1 deficiency alters leukocyte recruitment during $S$. aureus infection, wild type and $S d c 1^{-1-}$ mice were injected with a suspension of S. aureus IP and prepared for IVM after $4 \mathrm{~h}$. Control mice were injected IP with sterile saline. Numbers of 


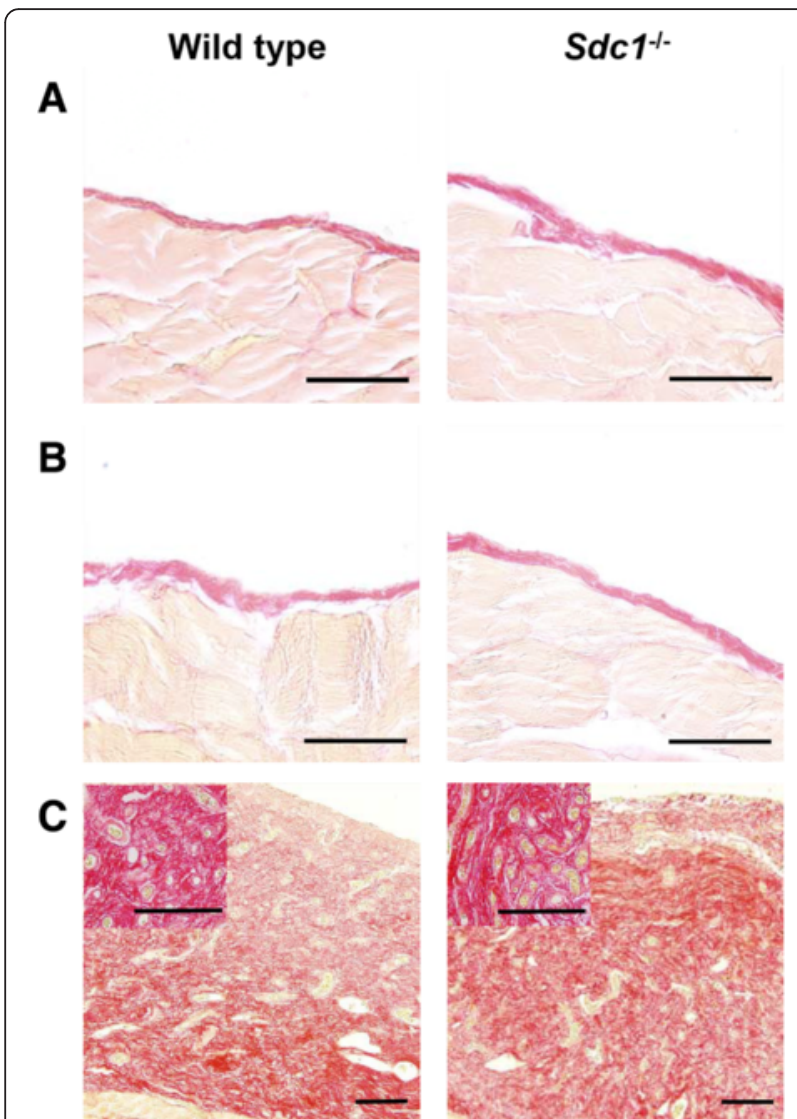

Fig. 5 Extensive collagen deposition in wild type and $\mathrm{Sdcl}^{-1-}$ mice with subacute peritoneal dialysis. At the study endpoint, samples of the abdominal wall were taken from (a) baseline control mice, (b) undialyzed animals that were injected with $S$. aureus and (c) mice that were treated with peritoneal dialysis for 4 weeks and infected with $\mathrm{S}$. aureus $4 \mathrm{~h}$ before the endpoint. The sections were stained with picro-sirius red to visualize collagen fibers. The thickened peritoneal layer of dialyzed mice was rich in collagen fibers that were disorganized in both, the wild type and $\mathrm{Sdcl}^{-/-}$mice. Representative images, $n=14$ mice in the wild type infected non-PD group and wild type PD group, $n=8$ mice in all other groups, (a \& $\mathbf{b})$ scale bar $=50$ $\mu \mathrm{m}$ and (c) scale bar $=100 \mu \mathrm{m}$

rolling leukocytes in mice infected with $S$. aureus were similar to saline controls (Fig. 9a). The number of adherent (Fig. 9b) and extravascular (Fig. 9c) leukocytes was significantly increased in S. aureus infection. However, there were no significant differences in the numbers of rolling, adherent and extravascular leukocytes between wild type and $S d \mathrm{Cl}^{-1-}$ mice. Thus, syndecan-1 does not modulate leukocyte trafficking in peritoneal venules during S. aureus infection.

\section{Discussion}

$S d c 1^{-1-}$ mice were reported to have abnormal phenotypes in injury and infection models [11, 17, 27-29]. In this study, we examined whether the abnormal phenotypes associated with syndecan-1 deficiency occur in PD. We

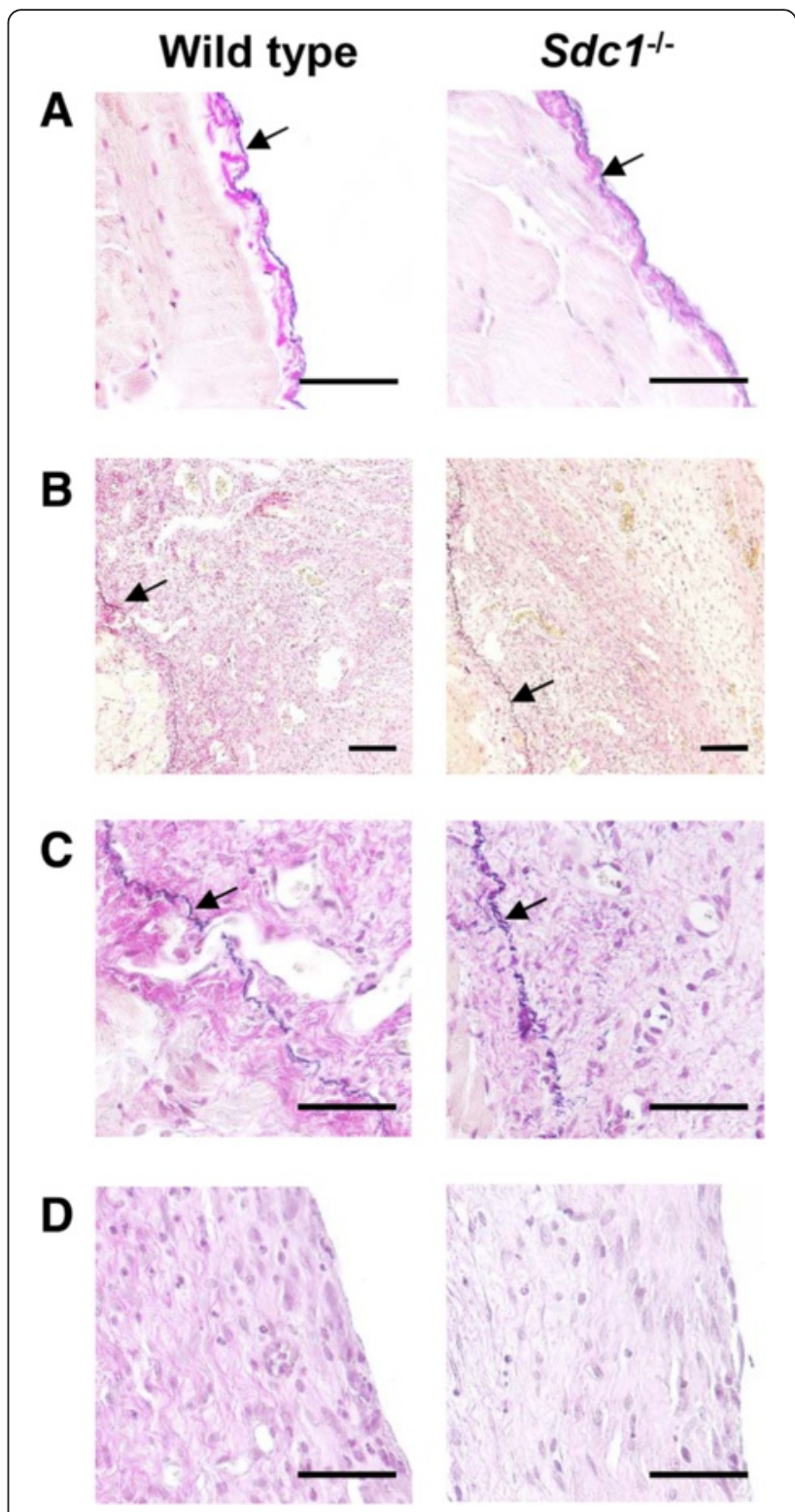

Fig. 6 Similar changes in elastic tissue in wild type and $S d c r^{-1-}$ mice with subacute peritoneal dialysis. Sections of the abdominal wall from (a) $S$. aureus-infected undialyzed control mice and (b) S. aureus-infected animals that were treated with peritoneal dialysis for 4 weeks were stained with resorcin-fuchsin and counterstained with van Gieson's solution and Weigert's iron hematoxylin to identify elastic fibers (indicated by arrows). a The network of elastic fibers was near the mesothelial surface in the undialyzed animals but was far below the mesothelial surface in the (c) dialyzed wild type and $\mathrm{Sdcl}^{-1-}$ animals. $\mathbf{d}$ Elastic fibers were not observed near the mesothelial surface in the dialyzed animals. Representative images, $n=14$ mice in the wild type groups and $n=8$ mice in the $S d c^{-1}{ }^{-1}$ groups, (a, c \& d) scale bar $=50 \mu \mathrm{m}$ and (b) scale bar $=100 \mu \mathrm{m}$

observed that histopathologic alterations of the peritoneum did not differ between $S d c 1^{-1-}$ and wild type mice. However, $S d \mathrm{Cl}^{-1-}$ mice were more susceptible to $S$. aureus infection, but only in the context of PD and despite 


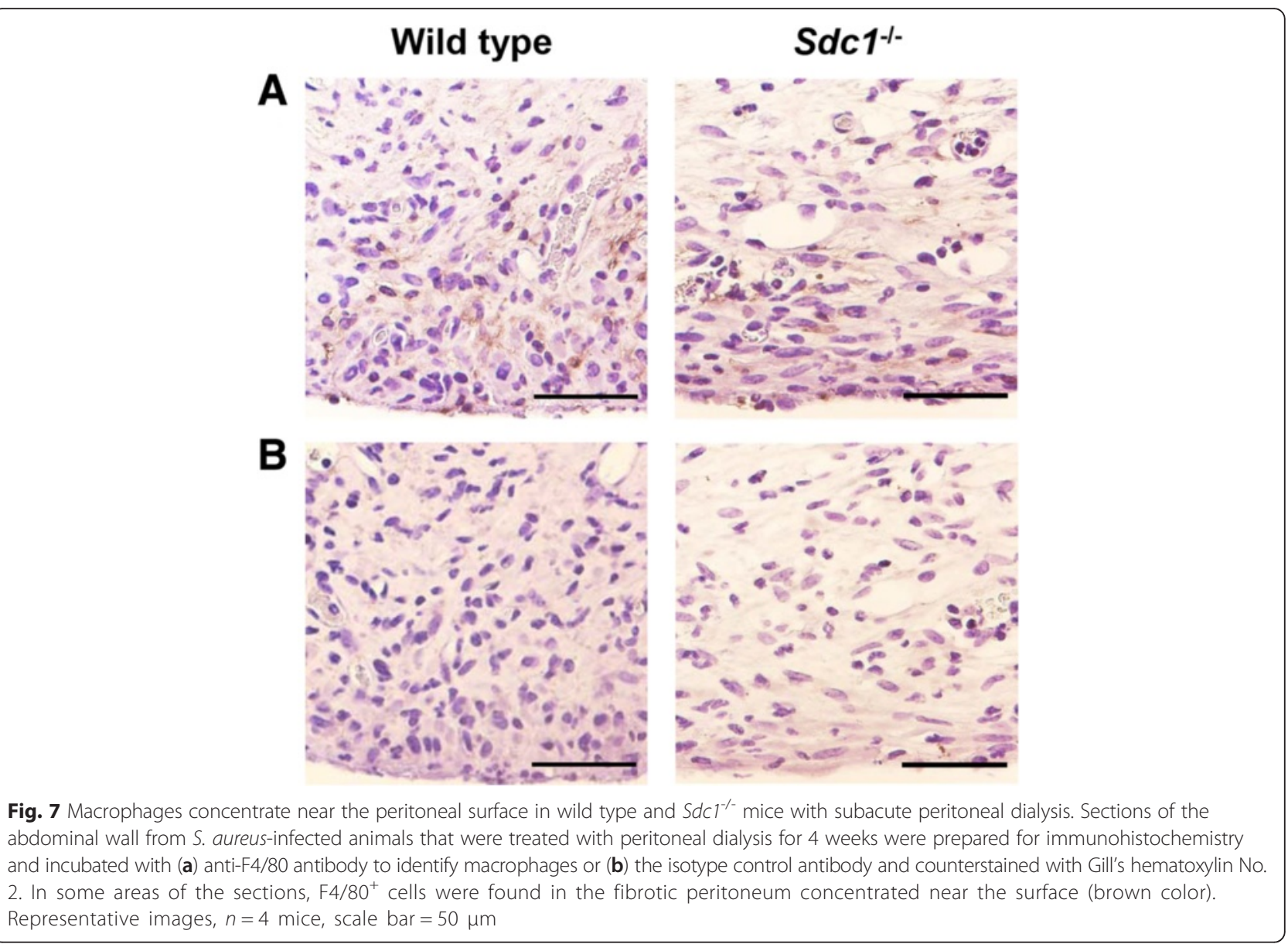

the fact that syndecan-1 deficiency did not affect leukocyte trafficking in $S$. aureus peritonitis. Thus, although syndecan-1 did not affect histopathology in PD, it was important for decreasing $S$. aureus dissemination.

Our observation that $S d \mathrm{Cl}^{-1-}$ mice were more susceptible to $S$. aureus colonization of the abdominal wall after 4 weeks of PD contrast with findings in the corneal tissue, where $S d c 1^{-1-}$ mice cleared $S$. aureus infection more effectively while $S$. aureus induced syndecan-1 shedding from the corneal epithelium in wild type animals [17]. Other studies also found protective effects of syndecan-1 deficiency during infections. Syndecan-1 deficiency protected mice in $P$. aeruginosa lung infection [30], and this pathogen was also found to promote syndecan-1 shedding. As well, $S d c 1^{-1-}$ mice had decreased mortality, less systemic bacterial dissemination and decreased cytokine production compared with wild type animals in a burn-wound model with $P$. aeruginosa infection [31]. One difference, however, is that these studies used injury models that are acute in nature, whereas our study involved 6-week exposure to a peritoneal catheter and 4week exposure to dialysis solution. Perhaps the ability of pathogens such as $S$. aureus to subvert syndecan-1 shedding to enhance pathogenesis is decreased in longer injury models. This idea raises the question whether $S d c 1^{-1-}$ mice in this long-term injury model would have similarly increased susceptibility to other pathogens, such as $P$. aeruginosa, during an acute peritoneal infection. Given that $P$. aeruginosa infection in syndecan-1 deficiency results in attenuated pro-inflammatory cytokine responses [31], it is plausible that increased susceptibility to this pathogen would also be observed in the $S d c 1^{-/-}$ mice with the subacute PD model during the first $4 \mathrm{~h}$ of infection where pro-inflammatory cytokines orchestrate the innate immune response to pathogen invasion.

The cytoplasmic domain of syndecan-1 binds cytoskeletal proteins and PDZ-domain proteins and, consequently, regulates remodelling of the actin cytoskeleton [32]. Syndecan-1 also mediates cell adhesion through its effects on integrins [33]. Not surprisingly, syndecan-1 deficiency was reported to impair epithelial barriers in injury and inflammation. After corneal wounding, $S d c 1^{-1}$ mice had decreased re-epithelialization, reduced $\alpha_{9}$-integrin localization and failure of apical repolarization of the tight junction protein zonula occludens (ZO)-1 [11]. Also, $S d c 1^{-1-}$ mice had decreased intestinal epithelial barrier function resulting in increased intestinal protein leakage, a finding that was replicated in human epithelium in vitro 


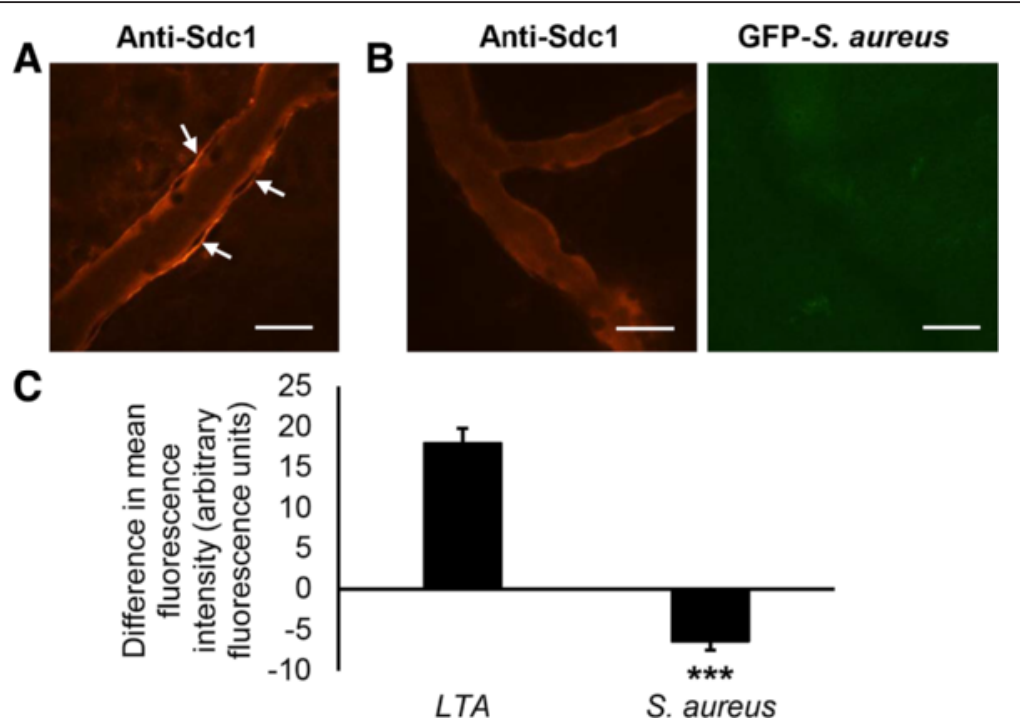

Fig. 8 S. aureus infection decreases subendothelial syndecan-1 levels of the peritoneal venules. Wild type mice were injected intraperitoneally with (a) $125 \mu \mathrm{g}$ of lipoteichoic acid (LTA) from S. aureus or (b) $1.8 \times 10^{8}$ colony-forming units of green fluorescent protein (GFP)-expressing S. aureus. After $4 \mathrm{~h}$, the mice were prepared for fluorescence intravital microscopy and Alexa Fluor ${ }^{\oplus 68}$-labeled anti-syndecan-1 antibodies were injected intravenously. The microcirculation of the parietal peritoneum was examined. Syndecan-1 was detected in the subendothelial compartment of venules in (a) LTA-stimulated mice (arrows) but not with (b) S. aureus infection. Representative images, scale bar $=20 \mu \mathrm{m}$. c Quantification of fluorescence intensity from the antibodies labeling the subendothelial surface showed that syndecan-1 protein expression during $S$. aureus infection was significantly decreased. Data recorded as mean \pm SEM and analyzed with Student's $t$-test, 4 venules averaged per mouse, $n=4$ mice, ${ }^{* * *} p<0.0001$ compared with LTA

[34]. Disruption of epithelial barriers is important in $S$. aureus pathogenesis. For example, in human airway epithelium, S. aureus caused disruption of actin and ZO-1 [35]. In this study, S. aureus activated proteolysis of junctional proteins to alter the epithelial barrier for transepithelial invasion. In human intestinal epithelium, $S$. aureus $\alpha$-toxin disrupted the barrier integrity with a reduction of cellular junctional proteins, namely ZO-1, ZO3 and E-cadherin [36]. Thus, another possibility is that the mesothelial layer of the $S d c 1^{-1-}$ mice in our study was more easily breached by $S$. aureus, resulting in increased invasion of the abdominal wall with subacute PD-induced injury. As well, given that decreased epithelial integrity mediates pathogen invasion in wounds, it is plausible that syndecan-1 deficiency during PD-induced injury would also lead to increased susceptibility to other pathogens such as $P$. aeruginosa, a common cause of wound infections [37].

Although syndecan-1 was shown to be involved in angiogenesis, in that $S d c 1^{-1-}$ mice exhibited increased corneal neovascularization in an angiogenesis assay [28] and syndecan-1 overexpression promoted tumor angiogenesis [12], we found that the increased vessel density in dialyzed animals was similar between $S d c 1^{-1-}$ and wild type mice. Furthermore, we found no evidence that fibrotic responses and collagen organization were altered in dialyzed $\mathrm{Sdcl}^{-1-}$ mice compared with wild type, even though altered phenotypes were noted by others in fibrotic mouse models. For example, in a mouse model of myocardial infarction, $S d c 1^{-1-}$ mice had elevated leukocyte recruitment and increased matrix metalloproteinase activity with increased collagen fragmentation and disorganization [29]. This phenotype also involved increased cardiac dilation and dysfunction. In an angiotensin II-induced cardiac fibrosis mouse model, however, $S d c 1^{-/-}$mice exhibited less cardiac fibrosis with decreased expression of collagen type I and III and reduced cardiac dysfunction [13]. Thus, the effects of syndecan-1 deficiency differ based on the fibrosis model. In transforming growth factor- $\beta 1$-induced peritoneal fibrosis, a secondary basement membrane was formed near the mesothelial surface, while remnants of the original basement membrane were found 50 to $100 \mu \mathrm{m}$ below the mesothelial surface in the rat peritoneum [38]. The peritoneal basement membrane is lined by a network of elastic fibers [39]. Our findings show that while the original layer of elastic fibers was several cell layers below the surface, a new network of elastic fibers was not formed near the mesothelial surface in PD, and this fibrotic response was not affected by syndecan-1 deficiency. As well, $S d c^{-1-}$ and wild type mice both had heterogeneous distribution of macrophages in the fibrotic tissue that were mostly concentrated near the peritoneal surface. Peritoneal fibrosis in PD models was shown to be largely due to a foreign body reaction to the catheter implant that contained a sterile cell layer of red 


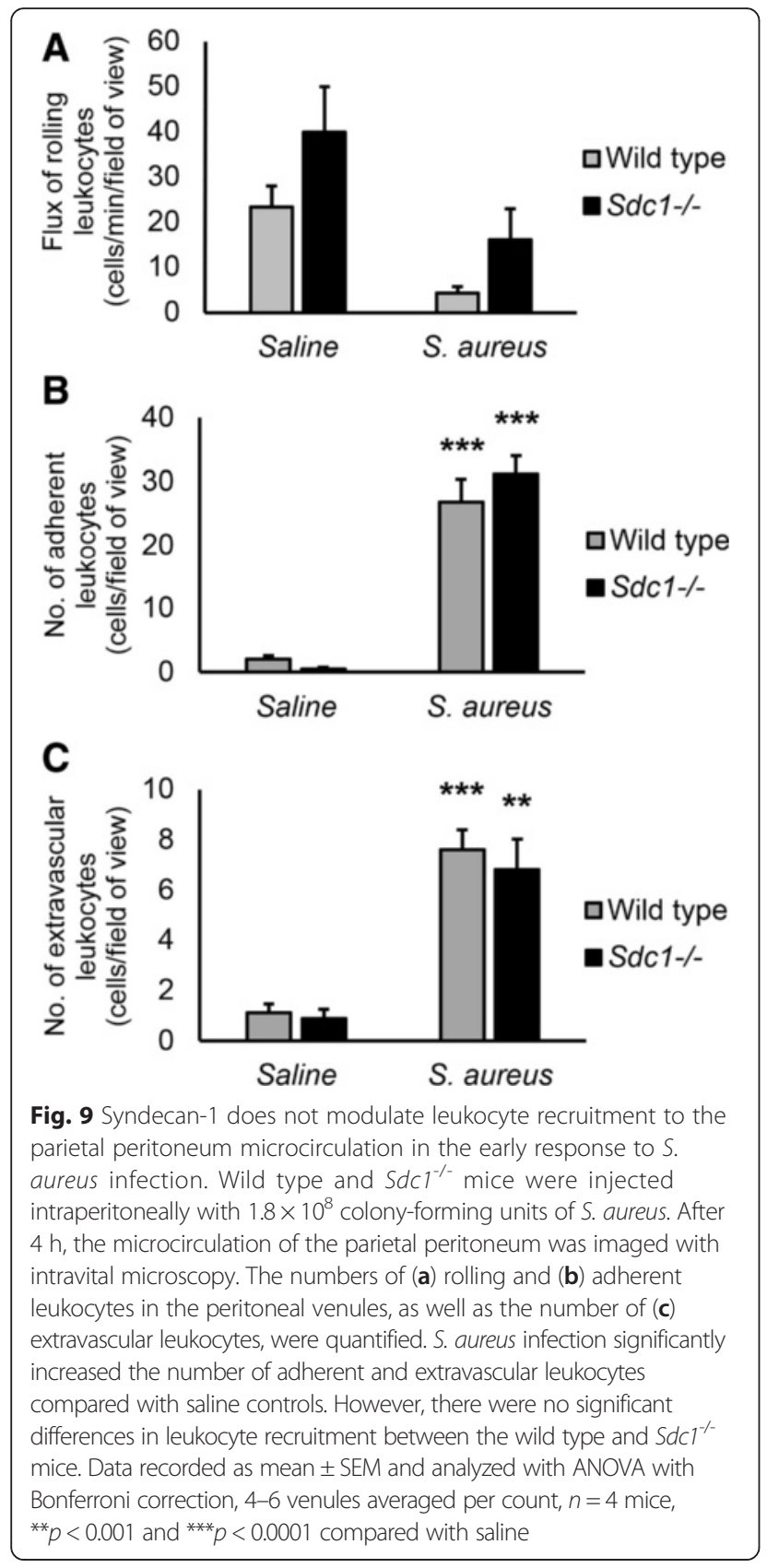

blood cells, leukocytes, mesothelial cells and fibroblasts [40]. Thus, the catheter acts as an inflammatory source in the peritoneum. Host material deposition and leukocyte recruitment to the catheter lumens were evident in our study, and the foreign body responses to the catheter biomaterial were similar between $S d c 1^{-1-}$ mice and wild type animals.

Previously, we found that syndecan-1 levels do not change in the parietal peritoneum microcirculation in response to $S$. aureus LTA [16], as LTA-challenged mice had subendothelial syndecan-1 levels that were similar to the saline-treated animals even though LTA induced leukocyte recruitment in the peritoneal microcirculation. This suggests that "sterile" inflammation does not promote syndecan-1 shedding. However, syndecan-1 shedding was repeatedly shown to be induced by pathogens [30, 41], such as S. aureus [17], and the microbial components that activate syndecan- 1 shedding from cellular membranes were deduced to be $S$. aureus $\alpha$ - and $\beta$ toxins [42]. These toxins induced syndecan-1 shedding by activating the host cell's protein-tyrosine kinasedependent shedding mechanisms [42]. In line with these results, we observed that $4 \mathrm{~h}$ after IP injection of a suspension of viable $S$. aureus cells, syndecan-1 levels in the subendothelial region of peritoneal venules were significantly diminished. Inflammatory cytokines regulate the expression of syndecan-1 at the protein and mRNA levels [43]. Therefore, in addition to the pathogen-induced shedding mechanisms, it is plausible that syndecan-1 expression in our study was affected by cytokines released in response to the S. aureus infection. Together, these findings indicate that $S$. aureus LTA-induced inflammation in the peritoneum does not model the inflammatory responses to viable $S$. aureus cells.

Although we observed dysentery and bacteremia, the $S$. aureus infection did not result in severely lowered systemic white blood cell counts that were seen in the cecal ligation and puncture model of sepsis [44]. Also, we did not see severely diminished leukocyte recruitment to peritoneal venules that was observed in the endotoxemia model of sepsis [16] and the mouse cremaster microcirculation during IP S. aureus infection [45]. However, in the cremaster muscle study, the dose of live $S$. aureus cells was higher than used in our study. We observed greater leukocyte recruitment in acute $S$. aureus infection in this study compared with the response to IP injection of $S$. aureus LTA observed in our previous work. Also, similar to our previous observations on peritoneal leukocyte recruitment in response to LTA, lipopolysaccharide or tumour necrosis factor- $\alpha$ (TNF $\alpha)$, there were no differences in leukocyte recruitment between wild type animals and $S d c 1^{-/-}$mice during infection [16]. Others reported that syndecan-1 deficiency in mice is associated with increased leukocyte recruitment in TNF $\alpha$-stimulated retinal and mesenteric microcirculation [28], naïve cremasteric venules [46], and during experimental autoimmune encephalomyelitis [47], delayedtype hypersensitivity response [48], and anti-glomerular basement membrane nephritis [49]. These different findings emphasize the uniqueness of the molecular mechanisms that regulate leukocyte recruitment in the parietal peritoneum. However, an important consideration is that in vitro work indicated that $S d c 1^{-1-}$ monocytes may be the dominant cell type in the increased leukocyte infiltrate [50], and higher numbers of monocytes are usually recruited in vivo after 3 to 4 days following peritonitis 
[51], which may explain our observations that $S d c 1^{-/-}$mice do not have elevated leukocyte recruitment in the early response to infection. Thus, it should be emphasized that our conclusions regarding the effects of syndecan-1 on infection and inflammation are only relevant to the early acute inflammatory responses after $4 \mathrm{~h}$ of infection.

\section{Conclusions}

Our study demonstrated that syndecan-1 deficiency does not impact histopathologic deterioration of the peritoneal layer in a mouse model of PD. Thus, despite the clinical relevance of syndecan-1 in the prognosis of diseases such as multiple myeloma [52], and sepsis [53], syndecan-1 does not appear to be important in PD-induced pathology. We did, however, find that syndecan-1 is important for limiting acute peritoneal $S$. aureus infection, which may have implications for incidence of peritonitis and infections in PD patients. Alongside current literature, the seemingly contrasting observations emphasize that syndecan-1 functions are cell- and tissue-specific and call for a careful comparison between experimental models. Furthermore, future research should dissect the peritoneal responses to $S$. aureus at longer infection time points during syndecan- 1 deficiency and compare these responses with other major pathogens that cause peritonitis in PD in order to fully understand the role of syndecan- 1 in injury, infection and inflammation.

\section{Competing interests}

The authors declare that they have no competing interests.

\section{Authors' contributions}

PMK, LLB and AEFR contributed to the conception and design of the study. PMK carried out the animal experiments and acquired and analyzed the data. UTN helped with the microbiology work. All authors contributed to the drafting of the manuscript or critical revising. All authors read and approved the final manuscript.

\section{Acknowledgments}

We thank Dr. Pyong Woo Park, Children's Hospital, Harvard Medical School, Boston, MA, USA, for providing the syndecan-1-deficient mice. We are also thankful to Marcia Reid, Electron Microscopy Facility, McMaster University, Hamilton, ON, Canada, for assistance with scanning electron microscopy. This work was supported by internal funding from the Department of Medicine, McMaster University. The funders had no role in study design, data collection and analysis, decision to publish, or preparation of the manuscript.

\section{Author details}

${ }^{1}$ Thrombosis and Atherosclerosis Research Institute and the Department of Medicine, McMaster University, Hamilton, ON, Canada. ${ }^{2}$ Department of Biochemistry and Biomedical Sciences and the Michael G. DeGroote Institute for Infectious Diseases Research, McMaster University, Hamilton, ON, Canada. ${ }^{3}$ David Braley Cardiac, Vascular and Stroke Research Institute, C5-106, 237 Barton Street East, Hamilton, ON L8L 2X2, Canada.

Received: 7 July 2015 Accepted: 12 January 2016

Published online: 01 February 2016

\section{References}

1. Kolesnyk I, Dekker FW, Boeschoten EW, Krediet RT. Time-dependent reasons for peritoneal dialysis technique failure and mortality. Perit Dial Int. 2010;30(2):170-7.
2. Barone RJ, Campora MI, Gimenez NS, Ramirez L, Santopietro M, Grbavac D, et al. Peritoneum: a noble membrane in long-term dialysis treatment. Adv Perit Dial. 2009;25:80-4.

3. Davies SJ, Phillips L, Griffiths AM, Russell LH, Naish PF, Russell GI. What really happens to people on long-term peritoneal dialysis? Kidney Int. 1998;54(6):2207-17.

4. Yung S, Chan TM. Mesothelial cells. Perit Dial Int. 2007;27 Suppl 2:S110-5.

5. Williams JD, Craig KJ, Topley N, Von Ruhland C, Fallon M, Newman GR, et al. Morphologic changes in the peritoneal membrane of patients with renal disease. J Am Soc Nephrol. 2002;13(2):470-9.

6. Williams JD, Craig K, von Ruhland C, Topley N, Williams GT, Biopsy Registry Study G. The natural course of peritoneal membrane biology during peritoneal dialysis. Kidney Int Suppl. 2003;88:S43-9.

7. Kavanagh D, Prescott GJ, Mactier RA. Peritoneal dialysis-associated peritonitis in Scotland (1999-2002). Nephrol Dial Transplant. 2004;19(10):2584-91.

8. Quintanar Lartundo JA, Palomar R, Dominguez-Diez A, Salas C, Ruiz-Criado J, Rodrigo E, et al. Microbiological profile of peritoneal dialysis peritonitis and predictors of hospitalization. Adv Perit Dial. 2011;27:38-42.

9. Piraino B, Bernardini J, Florio T, Fried L. Staphylococcus aureus prophylaxis and trends in gram-negative infections in peritoneal dialysis patients. Perit Dial Int. 2003;23(5):456-9.

10. Li Q, Park PW, Wilson CL, Parks WC. Matrilysin shedding of syndecan-1 regulates chemokine mobilization and transepithelial efflux of neutrophils in acute lung injury. Cell. 2002;111(5):635-46.

11. Stepp MA, Gibson HE, Gala PH, Iglesia DD, Pajoohesh-Ganji A, Pal-Ghosh S, et al. Defects in keratinocyte activation during wound healing in the syndecan-1-deficient mouse. J Cell Sci. 2002;115(Pt 23):4517-31.

12. Oh JH, Lee HS, Park SH, Ryu HS, Min CK. Syndecan-1 overexpression promotes tumor growth and angiogenesis in an endometrial cancer xenograft model. Int J Gynecol Cancer. 2010;20(5):751-6.

13. Schellings MW, Vanhoutte D, van Almen GC, Swinnen M, Leenders J J, Kubben N, et al. Syndecan-1 amplifies angiotensin II-induced cardiac fibrosis. Hypertension. 2010;55(2):249-56.

14. Kato M, Saunders S, Nguyen H, Bernfield M. Loss of cell surface syndecan-1 causes epithelia to transform into anchorage-independent mesenchyme-like cells. Mol Biol Cell. 1995;6(5):559-76.

15. Masola V, Gambaro G, Tibaldi E, Brunati AM, Gastaldello A, D'Angelo A, et al. Heparanase and syndecan-1 interplay orchestrates fibroblast growth factor-2-induced epithelial-mesenchymal transition in renal tubular cells. J Biol Chem. 2012;287(2):1478-88.

16. Kowalewska PM, Patrick AL, Fox-Robichaud AE. Syndecan-1 in the mouse parietal peritoneum microcirculation in inflammation. PLoS One. 2014;9(9), e104537.

17. Hayashida A, Amano S, Park PW. Syndecan-1 promotes Staphylococcus aureus corneal infection by counteracting neutrophil-mediated host defense. J Biol Chem. 2011;286(5):3288-97.

18. Yung S, Chan TM. Peritoneal proteoglycans: much more than ground substance. Perit Dial Int. 2007;27(4):375-90.

19. Kilkenny C, Browne W, Cuthill IC, Emerson M, Altman DG, Group NCRRGW. Animal research: reporting in vivo experiments: the ARRIVE guidelines. $\mathrm{Br} J$ Pharmacol. 2010;160(7):1577-9.

20. Kowalewska PM, Margetts PJ, Fox-Robichaud AE. Peritoneal dialysis catheter increases leukocyte recruitment in the mouse parietal peritoneum microcirculation and causes fibrosis. Perit Dial Int. 2016;36(1):7-15.

21. Sayedyahossein S, Xu SX, Rudkouskaya A, McGavin MJ, McCormick JK, Dagnino L. Staphylococcus aureus keratinocyte invasion is mediated by integrin-linked kinase and Rac1. FASEB J. 2015;29(2):711-23.

22. Kowalewska PM, Burrows LL, Fox-Robichaud AE. Intravital microscopy of the murine urinary bladder microcirculation. Microcirculation. 2011;18(8):613-22.

23. Anderson JM, Defife K, McNally A, Collier T, Jenney C. Monocyte, macrophage and foreign body giant cell interactions with molecularly engineered surfaces. J Mater Sci Mater Med. 1999;10(10/11):579-88.

24. Angsana J, Chen J, Smith S, Xiao J, Wen J, Liu L, et al. Syndecan-1 modulates the motility and resolution responses of macrophages. Arterioscler Thromb Vasc Biol. 2015;35(2):332-40.

25. Bellon T, Martinez V, Lucendo B, del Peso G, Castro MJ, Aroeira LS, et al. Alternative activation of macrophages in human peritoneum: implications for peritoneal fibrosis. Nephrol Dial Transplant. 2011;26(9):2995-3005.

26. Wang J, Jiang ZP, Su N, Fan JJ, Ruan YP, Peng WX, et al. The role of peritoneal alternatively activated macrophages in the process of peritoneal fibrosis related to peritoneal dialysis. Int J Mol Sci. 2013;14(5):10369-82. 
27. Ojeh N, Hiilesvuo K, Warri A, Salmivirta M, Henttinen T, Maatta A. Ectopic expression of syndecan-1 in basal epidermis affects keratinocyte proliferation and wound re-epithelialization. J Invest Dermatol. 2008;128(1):26-34.

28. Gotte M, Joussen AM, Klein C, Andre P, Wagner DD, Hinkes MT, et al. Role of syndecan-1 in leukocyte-endothelial interactions in the ocular vasculature. Invest Ophthalmol Vis Sci. 2002;43(4):1135-41.

29. Vanhoutte D, Schellings MW, Gotte M, Swinnen M, Herias V, Wild MK, et al Increased expression of syndecan-1 protects against cardiac dilatation and dysfunction after myocardial infarction. Circulation. 2007;115(4):475-82.

30. Park PW, Pier GB, Hinkes MT, Bernfield M. Exploitation of syndecan-1 shedding by Pseudomonas aeruginosa enhances virulence. Nature. 2001; 411(6833):98-102.

31. Haynes 3rd A, Ruda F, Oliver J, Hamood AN, Griswold JA, Park PW, et al. Syndecan 1 shedding contributes to Pseudomonas aeruginosa sepsis. Infect Immun. 2005;73(12):7914-21.

32. Chakravarti R, Sapountzi V, Adams JC. Functional role of syndecan-1 cytoplasmic $V$ region in lamellipodial spreading, actin bundling, and cell migration. Mol Biol Cell. 2005;16(8):3678-91.

33. Altemeier WA, Schlesinger SY, Buell CA, Brauer R, Rapraeger AC, Parks WC, et al. Transmembrane and extracellular domains of syndecan-1 have distinct functions in regulating lung epithelial migration and adhesion. J Biol Chem. 2012;287(42):34927-35.

34. Bode L, Salvestrini C, Park PW, Li JP, Esko JD, Yamaguchi Y, et al. Heparan sulfate and syndecan-1 are essential in maintaining murine and human intestinal epithelial barrier function. J Clin Invest. 2008;118(1):229-38.

35. Soong G, Martin FJ, Chun J, Cohen TS, Ahn DS, Prince A. Staphylococcus aureus protein A mediates invasion across airway epithelial cells through activation of RhoA GTPase signaling and proteolytic activity. J Biol Chem. 2011;286(41):35891-8.

36. Kwak YK, Vikstrom E, Magnusson KE, Vecsey-Semjen B, Colque-Navarro P, Mollby R. The Staphylococcus aureus alpha-toxin perturbs the barrier function in Caco-2 epithelial cell monolayers by altering junctional integrity. Infect Immun. 2012;80(5):1670-80

37. Serra R, Grande R, Butrico L, Rossi A, Settimio UF, Caroleo B, et al. Chronic wound infections: the role of Pseudomonas aeruginosa and Staphylococcus aureus. Expert Rev Anti Infect Ther. 2015;13(5):605-13.

38. Margetts PJ, Bonniaud P, Liu L, Hoff CM, Holmes CJ, West-Mays JA, et al. Transient overexpression of TGF-\{beta\}1 induces epithelial mesenchymal transition in the rodent peritoneum. J Am Soc Nephrol. 2005;16(2):425-36.

39. Knudsen PJ. The peritoneal elastic lamina. J Anat. 1991;177:41-6.

40. Flessner MF, Credit K, Richardson K, Potter R, Li X, He Z, et al. Peritoneal inflammation after twenty-week exposure to dialysis solution: effect of solution versus catheter-foreign body reaction. Perit Dial Int. 2010;30(3):284-93

41. Chen Y, Hayashida A, Bennett AE, Hollingshead SK, Park PW. Streptococcus pneumoniae sheds syndecan-1 ectodomains through ZmpC, a metalloproteinase virulence factor. J Biol Chem. 2007;282(1):159-67.

42. Park PW, Foster TJ, Nishi E, Duncan SJ, Klagsbrun M, Chen Y. Activation of syndecan-1 ectodomain shedding by Staphylococcus aureus alpha-toxin and beta-toxin. J Biol Chem. 2004;279(1):251-8.

43. Day RM, Mitchell TJ, Knight SC, Forbes A. Regulation of epithelial syndecan-1 expression by inflammatory cytokines. Cytokine. 2003;21(5):224-33.

44. Ondiveeran HK, Fox-Robichaud AE. Pentastarch in a balanced solution reduces hepatic leukocyte recruitment in early sepsis. Microcirculation. 2004;11(8):679-87.

45. Yipp BG, Andonegui G, Howlett CJ, Robbins SM, Hartung T, Ho M, et al. Profound differences in leukocyte-endothelial cell responses to lipopolysaccharide versus lipoteichoic acid. J Immunol. 2002;168(9):4650-8.

46. Savery MD, Jiang JX, Park PW, Damiano ER. The endothelial glycocalyx in syndecan-1 deficient mice. Microvasc Res. 2013;87:83-91.

47. Zhang X, Wu C, Song J, Gotte M, Sorokin L. Syndecan-1, a cell surface proteoglycan, negatively regulates initial leukocyte recruitment to the brain across the choroid plexus in murine experimental autoimmune encephalomyelitis. J Immunol. 2013;191(9):4551-61.

48. Masouleh BK, Ten Dam GB, Wild MK, Seelige R, van der Vlag J, Rops AL, et al. Role of the heparan sulfate proteoglycan syndecan-1 (CD138) in delayed-type hypersensitivity. J Immunol. 2009;182(8):4985-93.

49. Rops AL, Gotte M, Baselmans MH, van den Hoven MJ, Steenbergen EJ, Lensen JF, et al. Syndecan-1 deficiency aggravates anti-glomerular basement membrane nephritis. Kidney Int. 2007:72(10):1204-15.
50. Gotte M, Bernfield M, Joussen AM. Increased leukocyte-endothelial interactions in syndecan-1-deficient mice involve heparan sulfatedependent and -independent steps. Curr Eye Res. 2005;30(6):417-22.

51. Hurst SM, Wilkinson TS, McLoughlin RM, Jones S, Horiuchi S, Yamamoto N, et al. II-6 and its soluble receptor orchestrate a temporal switch in the pattern of leukocyte recruitment seen during acute inflammation. Immunity. 2001;14(6):705-14

52. Dhodapkar MV, Kelly T, Theus A, Athota AB, Barlogie B, Sanderson RD. Elevated levels of shed syndecan-1 correlate with tumour mass and decreased matrix metalloproteinase- 9 activity in the serum of patients with multiple myeloma. Br J Haematol. 1997:99(2):368-71.

53. Nelson A, Berkestedt I, Schmidtchen A, Ljunggren L, Bodelsson M. Increased levels of glycosaminoglycans during septic shock: relation to mortality and the antibacterial actions of plasma. Shock. 2008;30(6):623-7.

\section{Submit your next manuscript to BioMed Central and we will help you at every step:}

- We accept pre-submission inquiries

- Our selector tool helps you to find the most relevant journal

- We provide round the clock customer support

- Convenient online submission

- Thorough peer review

- Inclusion in PubMed and all major indexing services

- Maximum visibility for your research

Submit your manuscript at www.biomedcentral.com/submit
Ciomed Central 